\title{
Prognostic significance of infarct core pathology in ST-elevation myocardial infarction survivors revealed by quantitative $\mathrm{T2}$-weighted cardiac magnetic resonance
}

\author{
David Carrick ${ }^{2,1^{*}}$, Caroline Haig ${ }^{3}$, Samuli M Rauhalammi ${ }^{2}$, Nadeem Ahmed ${ }^{2}$, Ify Mordi ${ }^{2}$, Margaret McEntegart ${ }^{1}$, \\ Mark Petrie ${ }^{1}$, Hany Eteiba', Stuart Hood ${ }^{1}$, Stuart Watkins ${ }^{1}$, Mitchell Lindsay ${ }^{1}$, Ahmed Marous ${ }^{1}$, \\ Aleksandra Radjenovic ${ }^{2}$, lan Ford ${ }^{3}$, Niko Tzemos ${ }^{2}$, Keith G Oldroyd ${ }^{2,1}$, Colin Berry ${ }^{2,1}$
}

From 18th Annual SCMR Scientific Sessions

Nice, France. 4-7 February 2015

\section{Background}

Myocardial transverse relaxation time (T2, ms) is a fundamental magnetic property of tissue that is related to water content and mobility. The pathophysiological and prognostic importance of native myocardial $\mathrm{T} 2$ in acute ST-elevation myocardial infarction (STEMI) patients is unknown. We aimed to assess the clinical significance of native $\mathrm{T} 2$ within the infarct core using cardiac magnetic resonance (CMR) imaging.

\section{Methods}

We performed a prospective single center cohort study in reperfused STEMI patients who underwent CMR 2 days and 6 months post-MI. T2-weighted CMR (investigational prototype T2-prepared TrueFisp sequence) was measured in myocardial regions-of-interest. The infarct territory and microvascular obstruction were depicted with late gadolinium enhancement CMR. All-cause death or heart failure hospitalization was a prespecified outcome that was assessed during follow-up.

\section{Results}

324 STEMI patients (mean \pm SD age $59 \pm 12$ years, 237 males, 121 with anterior STEMI) gave informed consent and had CMR (14 July 2011 - 22 November 2012). All 324 had follow-up assessments (median duration 860 days). Infarct size was $18 \pm 14 \%$ of LV mass. One hundred and

${ }^{2}$ Institute of Cardiovascular and Medical Sciences, University of Glasgow, Glasgow, UK

Full list of author information is available at the end of the article sixty four (51\%) patients had late microvascular obstruction whereas 197 (61\%) patients had an infarct core revealed by native T2. Native T2 within the infarct core (53.9 \pm 4.8$)$ was higher than in the remote zone $(49.7 \pm 2.1$ $\mathrm{ms} ; \mathrm{p}<0.01)$ but lower than in the area-at-risk $(62.9 \pm 5.1$ $\mathrm{ms})(\mathrm{p}<0.01)$. In multivariable linear regression, native $\mathrm{T} 2$ in the infarct core was negatively associated with heart rate, Killip class, and peak neutrophil count at presentation (all $\mathrm{p}<0.05$ ).

Baseline T2 core (ms) was univariably associated with $\operatorname{LVEF}(0.31$ (0.04, 0.58); $\mathrm{p}=0.023)$. Baseline T2 core was not associated with LVEF or volumes at 6 months.

Thirty (10.4\%) patients died or experienced a heart failure event. These events included 5 cardiovascular deaths, 3 non-cardiovascular deaths and 22 episodes of heart failure (Killip Class 3 or 4 heart failure $(n=20)$ or defibrillator implantation $\mathrm{n}=2$ ). T2-core (ms) was associated with allcause death or heart failure hospitalization (hazard ratio 0.786, 95\% CI 0.658, 0.939; $\mathrm{p}=0.008$ ) including after adjustment for LVEF at baseline $(\mathrm{p}=0.017)$ or LV end-diastolic volume at baseline $(\mathrm{p}=0.009)$.

\section{Conclusions}

Infarct core revealed by native $\mathrm{T} 2$ was common and independently associated with all-cause death or heart failure hospitalization post-discharge.

\section{Funding}

N/A. 


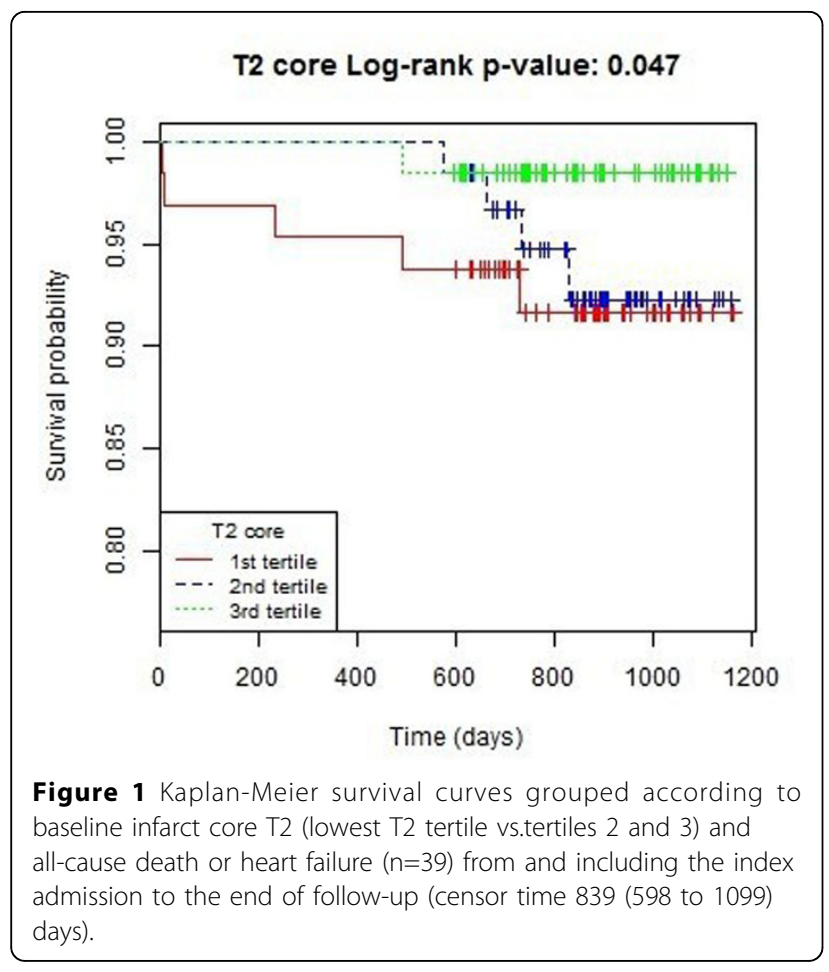

\section{Authors' details}

${ }^{1}$ Golden Jubilee National Hospital, Clydebank, UK. ${ }^{2}$ Institute of Cardiovascular and Medical Sciences, University of Glasgow, Glasgow, UK. ${ }^{3}$ Robertson Center for Biostatistics, University of Glasgow, Glasgow, UK.

Published: 3 February 2015

Cite this article as: Carrick et al:: Prognostic significance of infarct core pathology in ST-elevation myocardial infarction survivors revealed by quantitative T2-weighted cardiac magnetic resonance. Journal of Cardiovascular Magnetic Resonance 2015 17(Suppl 1):O54.

\section{Submit your next manuscript to BioMed Central} and take full advantage of:

- Convenient online submission

- Thorough peer review

- No space constraints or color figure charges

- Immediate publication on acceptance

- Inclusion in PubMed, CAS, Scopus and Google Scholar

- Research which is freely available for redistribution

Submit your manuscript at www.biomedcentral.com/submit
C Biomed Central 